\title{
Tracking Earth's Energy: From El Niño to Global Warming
}

\author{
Kevin E. Trenberth · John T. Fasullo
}

Received: 17 May 2011 / Accepted: 26 September 2011/Published online: 14 October 2011

(C) The Author(s) 2011. This article is published with open access at Springerlink.com

\begin{abstract}
The state of knowledge and outstanding issues with respect to the global mean energy budget of planet Earth are described, along with the ability to track changes over time. Best estimates of the main energy components involved in radiative transfer and energy flows through the climate system do not satisfy physical constraints for conservation of energy without adjustments. The main issues relate to the downwelling longwave (LW) radiation and the hydrological cycle, and thus the surface evaporative cooling. It is argued that the discrepancy is $18 \%$ of the surface latent energy flux, but only $4 \%$ of the downwelling LW flux and, for various reasons, it is most likely that the latter is astray in some calculations, including many models, although there is also scope for precipitation estimates to be revised. Beginning in 2000, the top-of-atmosphere radiation measurements provide stable estimates of the net global radiative imbalance changes over a decade, but after 2004 there is "missing energy" as the observing system of the changes in ocean heat content, melting of land ice, and so on is unable to account for where it has gone. Based upon a number of climate model experiments for the twenty-first century where there are stases in global surface temperature and upper ocean heat content in spite of an identifiable global energy imbalance, we infer that the main sink of the missing energy is likely the deep ocean below $275 \mathrm{~m}$ depth.
\end{abstract}

Keywords Earth's energy · Global warming · El Niño · Ocean heat content · Atmospheric radiation budget $\cdot$ Climate change

\section{Introduction}

Weather and climate on Earth are determined by the amount and distribution of incoming radiation from the sun. For a steady-state climate, global mean outgoing longwave

The National Center for Atmospheric Research is sponsored by the National Science Foundation.

K. E. Trenberth $(\bowtie) \cdot$ J. T. Fasullo

National Center for Atmospheric Research, Boulder, CO 80307, USA

e-mail: trenbert@ucar.edu 
radiation (OLR) necessarily balances the incoming absorbed solar radiation (ASR), but with redistributions of energy within the climate system to enable this to happen on a global basis. Incoming radiant energy may be scattered and reflected by clouds and aerosols or absorbed in the atmosphere. The transmitted radiation is then either absorbed or reflected at the Earth's surface. Radiant solar (shortwave) energy is transformed into sensible heat, latent energy (involving different water states), potential energy, and kinetic energy before being emitted as longwave infrared energy. Energy may be stored, transported in various forms, and converted among the different types, giving rise to a rich variety of weather or turbulent phenomena in the atmosphere and ocean. Moreover, the energy balance can be upset in various ways, changing the climate and associated weather.

Kiehl and Trenberth (1997) reviewed past estimates of the global mean flow of energy through the climate system and presented a best estimate of the budget based on various measurements and models, by taking advantage of various closure constraints. They also performed a number of radiative computations to examine the spectral features of the incoming and outgoing radiation and determined the role of clouds and various greenhouse gases in the overall radiative energy flows. At the top-of-atmosphere (TOA) values relied heavily on observations from the Earth Radiation Budget Experiment (ERBE) from 1985 to 1989 , when the TOA values were approximately in balance.

Fasullo and Trenberth (2008a) provide an assessment of the global energy budgets at TOA and the surface, for the global atmosphere, and ocean and land domains based on a synthesis of satellite retrievals, reanalysis fields, a land surface simulation, and ocean temperature estimates. As well as ERBE data, they made use of the newly available Clouds and the Earth's Radiant Energy System (CERES) measurements. They constrained the TOA budget to match estimates of the global imbalance associated with changes in atmospheric composition and climate. They included an assessment of sampling errors and the differences between the ERBE and CERES measurements. There is an annual mean transport of energy by the atmosphere from ocean to land regions of $2.2 \pm 0.1 \mathrm{PW}$ (Petawatts $=10^{15} \mathrm{~W}$ ) primarily in the northern winter when the transport exceeds $5 \mathrm{PW}$. Fasullo and Trenberth (2008b) went on to evaluate the temporal and spatial characteristics of meridional atmospheric energy transports for ocean, land, and global domains, while Trenberth and Fasullo (2008) delved into the ocean heat budget in considerable detail and provided an observationally based estimate of the mean and annual cycle of ocean energy divergence and a comprehensive assessment of uncertainty.

\section{The Global Energy Budget}

Trenberth et al. (2009) updated the Kiehl and Trenberth (1997) global energy flow diagram (Fig. 1) based on CERES measurements from March 2000 to November 2005, which include improvements in retrieval methodology and hardware, including its exploitation of MODIS (Moderate Resolution Imaging Spectro-radiometer) retrievals for scene identification, and they discussed continuing sources of uncertainty. These results built on the results of Fasullo and Trenberth (2008a, b) to update other parts of the energy cycle and flows through the atmosphere. To help understand sources of error and the discrepancies among various estimates, a breakdown of the budgets into land and ocean domains and a consideration of the annual and diurnal cycles were included. The TOA energy imbalance can probably be most accurately determined from climate models, and Fasullo and Trenberth (2008a) deduced the imbalance to be $0.9 \mathrm{~W} \mathrm{~m}^{-2}$, where the error bars are $\pm 0.5 \mathrm{~W} \mathrm{~m}^{-2}$. Figure 1 is modified slightly from that originally published, as discussed 


\section{Global Energy Flows $\mathrm{W} \mathrm{m}^{-2}$}

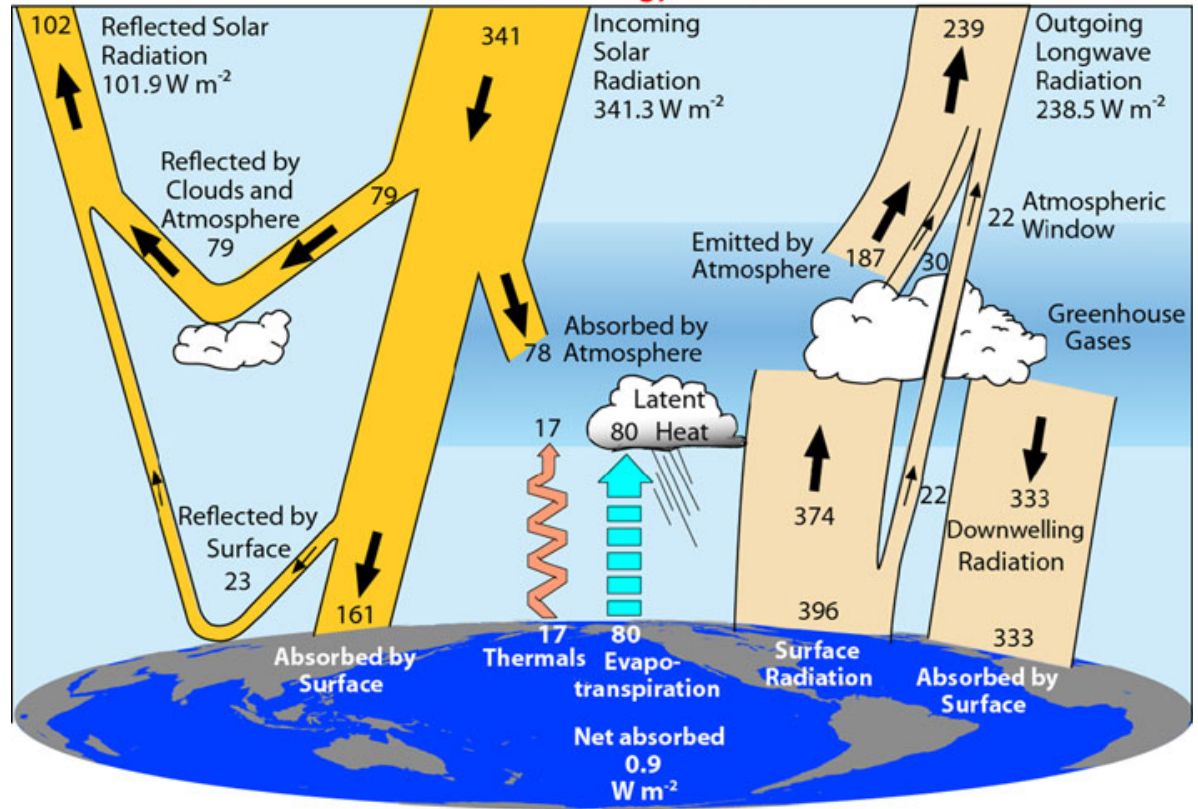

Fig. 1 The global annual mean earth's energy budget for 2000-2005 (W m $\left.{ }^{-2}\right)$. The broad arrows indicate the schematic flow of energy in proportion to their importance. Adapted from Trenberth et al. (2009) with changes noted in the text

below. Uncertainties are discussed in Trenberth et al. (2009) and are mostly not dealt with here, except to highlight some sources of discrepancy with other studies.

In Fig. 1, use has been made of conservation of energy and the assumption that, on a time scale of years, the change in heat storage within the atmosphere is very small. Accordingly, the net radiation at TOA $R_{\mathrm{T}}$ is the sum of the ASR minus the OLR: $R_{\mathrm{T}}=\mathrm{ASR}-\mathrm{OLR}$. In turn, the ASR is the difference between the incoming solar radiation and the reflected solar radiation. At the surface, the ASR has to be offset by the sensible heat and latent heat fluxes plus the net longwave radiation. The latter is made up of two large terms: the emitted radiation from the surface and the downwelling longwave radiation coming back from the atmosphere. Both at the surface and TOA the imbalance is the same and, as noted above, is estimated to be $0.9 \mathrm{~W} \mathrm{~m}^{-2}$.

Updates in Trenberth et al. (2009) included revised absorption in the atmosphere by water vapor and aerosols, since Kim and Ramanathan (2008) found that updated spectroscopic parameters and continuum absorption for water vapor increased the absorption by 4-6 $\mathrm{W} \mathrm{m}^{-2}$. The sensible heat has values of 17,27 , and $12 \mathrm{~W} \mathrm{~m}^{-2}$ for the globe, land, and ocean (just over $70 \%$ of the Earth), and, even with uncertainties of $10 \%$, the errors are only order $2 \mathrm{~W} \mathrm{~m}^{-2}$. There is widespread agreement that the global mean surface upward longwave (LW) radiation is about $396 \mathrm{~W} \mathrm{~m}^{-2}$, which is dependent on the skin temperature and surface emissivity (Zhang et al. 2006).

Global precipitation should equal global evaporation for a long-term average, and estimates are likely more reliable of the former. However, there is considerable uncertainty in precipitation over both the oceans and land (Trenberth et al. 2007b; Schlosser and Houser 2007). The latter is mainly due to wind effects, undercatch, and sampling, while the 
former is due to shortcomings in remote sensing. Global Precipitation Climatology Project (GPCP) values (Huffman et al. 2009) are considered most reliable for precipitation (Trenberth et al. 2007b), while results from CloudSat (e.g., Stephens and Haynes 2007) may help improve on these, with prospects mainly for increases in precipitation owing to undersampling low warm clouds. Consequently, the GPCP values are considered to be likely somewhat low. Accordingly, Trenberth et al. (2009) increased the GPCP values over oceans by $5 \%$ and the global value assigned was $80.0 \mathrm{~W} \mathrm{~m}^{-2}(2.76 \mathrm{~mm} / \mathrm{day})$. The latent heat flux values were apportioned between ocean and land as in Trenberth et al. (2007a) by assuming an observationally based runoff into the ocean of $40 \times 10^{3} \mathrm{~km}^{3} \mathrm{year}^{-1}$ (Trenberth et al. 2007a). The land precipitation from GPCP is $2.06 \mathrm{~mm} /$ day, while the ocean precipitation was deduced to be $3.06 \mathrm{~mm} /$ day, reasonably close to estimates of latent heat flux from $\mathrm{Yu}$ and Weller (2007).

The downward and net LW radiation were computed as a residual. After the adjustments noted above for latent heat and better accounting for the effects of aerosols and water vapor in the ASR, the revised estimates are 333 and $63 \mathrm{~W} \mathrm{~m}^{-2}$ for the downward and net surface LW. Wild et al. (2001) proposed that $344 \mathrm{~W} \mathrm{~m}^{-2}$ is a best estimate from models but noted that considerable uncertainties exist and especially that there were problems in accurate simulation of thermal emission from a cold, dry, cloud-free atmosphere, and a dependence on water vapor content. The latter may relate to the formulation of the water vapor continuum. The correct simulation of low clouds is also a continuing challenge for models and is likely to also exist as a source of major model bias in downward LW flux. Costa and Shine (2011) have recomputed the amount of radiation from the surface that actually reaches space under clear sky and cloudy conditions, which is a preferred method than simply assigning a value based on the so-called atmospheric window, as Kiehl and Trenberth (1997) did, and the value globally is $22 \mathrm{~W} \mathrm{~m}^{-2}$. This has been incorporated in the version of the global atmospheric flows in Fig. 1.

It has been argued that downward LW radiation is likely to be underestimated owing to the view from satellites which will miss underlying low clouds and overestimate cloud base height. Zhang et al. (2006) found that the surface LW flux was very sensitive to assumptions about tropospheric water vapor and temperatures but did not analyze the dependence on clouds. Yet, the characteristics of clouds on which the back radiation is most dependent, such as cloud base, are not well determined from conventional spacebased measurements and hence the need for missions such as CloudSat (e.g., Stephens et al. 2002; Haynes and Stephens 2007). Preliminary downwelling LW radiation estimates based on Cloudsat variables indeed suggest values even higher $\left(347 \pm 7 \mathrm{~W} \mathrm{~m}^{-2} ; \pm 1 \sigma\right)$ (Kato et al. 2011). Yet, considerable uncertainty remains, even in this estimate. For example, there are sources of error in how the 3-D heterogeneity of clouds is treated, and there is no unique way to treat the effects of overlap on the downward flux, although Cloudsat information can help. For clouds at all levels, emissivity assumptions will affect the estimated downward LW flux, and the amount of water vapor between the surface and the cloud base is a challenge to quantify. In the tropics, the effect of continuum absorption also strongly affects the impact of cloud emission on surface LW fluxes.

From surface closure constraints, however, it is very difficult to accommodate these higher estimates of the downwelling LW radiation, which if changed from 333 to $347 \mathrm{~W} \mathrm{~m}^{-2}$ would require an accommodation of an extra $14 \mathrm{~W} \mathrm{~m}^{-2}$ in other terms of the surface budget. The estimate of the incoming solar at the surface is, if anything, low, as the aerosol and water vapor absorption is now more likely to be slightly overestimated. Indeed, Kato et al. (2011) have a value $8 \mathrm{~W} \mathrm{~m}^{-2}$ higher, further exacerbating their surface energy imbalance. The sensible heat and outgoing surface LW radiation estimates are fairly well 
constrained. This leaves only the surface evaporative cooling, which is balanced by global precipitation, as the term to accommodate such an increase. The value used for the surface latent energy flux is already increased over available estimates, as noted above. Our current assessment is that further uncertainties might enable that value to increase to perhaps $85 \mathrm{~W} \mathrm{~m}^{-2}$, but that seems to be the upper limit of current uncertainties in precipitation retrieval. The extra $14 \mathrm{~W} \mathrm{~m}^{-2}$ makes up $18 \%$ of the surface latent energy flux but is only $4 \%$ of the downwelling LW flux. Accordingly, our assessment is that it is most likely that the latter is seriously astray in some calculations, including many models.

\section{Changes in Energy Balance Over the Past Decade}

With the successes of CERES, variability in the net radiative incoming energy at the TOA can now be measured to within $0.1 \mathrm{~W} \mathrm{~m}^{-2}$ year $^{-1}$. Thus, a key objective is to track the flow of such anomalies through the system over time in order to address the question as to how variability in energy fluxes is linked to climate variability. The main energy reservoir is the ocean, and the exchange of energy between the atmosphere and ocean is ubiquitous, so that heat once sequestered can resurface at a later time to affect weather and climate on a global scale. Thus, a change in the energy balance has consequences, sooner or later, for the climate. Moreover, we have observing systems in place that nominally can measure the major storage and flux terms, but due to errors and uncertainty it remains a challenge to track anomalies with confidence.

A climate event, such as the drop in surface temperatures over North America in 2008 (Perlwitz et al. 2009), is often stated to be due to natural variability, as if this fully accounts for what has happened. Aside from weather events that primarily arise from instabilities in the atmosphere, natural climate variability has a cause. Its origins may be external to the climate system: a change in the sun, a volcanic eruption, or Earth's orbital changes that ring in the major glacial to interglacial swings. Or its origins may be internal to the climate system and arise from interactions between the atmosphere, oceans, cryosphere, and land surface, which depend on the very different thermal inertia of these components.

\subsection{El Niño}

As an example of natural variability, the biggest El Niño in the modern record by many measures occurred in 1997-1998. Successful warnings were issued a few months in advance regarding the unusual and disruptive weather across North America and around the world and were possible in part because the energy that sustains El Niño was tracked in the ocean by a new moored buoy observing system in the Tropical Pacific. Typically prior to an El Niño, in La Niña conditions, the cold sea waters in the central and eastern tropical Pacific create high atmospheric pressure and clear skies, with plentiful sunshine heating the ocean waters. The ocean currents redistribute the ocean heat which builds up in the tropical western Pacific Warm Pool until an El Niño provides relief (Trenberth et al. 2002). The spread of warm waters across the Pacific in collaboration with changing winds in turn promotes evaporative cooling of the ocean, moistening the atmosphere, and fueling tropical storms and convection over and around the anomalously warm waters. The changed atmospheric heating alters the jet streams and storm tracks and influences weather patterns for the duration of the event (Trenberth et al. 1998).

In 2007-2008, a strong La Niña event that spilled over to the 2008-2009 northern winter had direct repercussions for cooler weather across North America and elsewhere 
(Perlwitz et al. 2009). But, by June 2009, the situation had reversed as the next El Niño emerged and grew to be a moderate event, with temperatures in the top $150 \mathrm{~m}$ of the ocean above normal by as much as $5^{\circ} \mathrm{C}$ across the equatorial Pacific in December 2009. Multiple storms barreled into Southern California in January 2010, consistent with expectations from the El Niño. The El Niño continued until May 2010 but abruptly reversed to become a strong La Niña by July 2010.

We can often recognize these changes once they have occurred, and they permit some level of climate forecast skill. But a major challenge is to be able to track the energy associated with such variations more thoroughly: Where did the heat for the 2009-2010 El Niño actually come from? Where did the heat suddenly disappear to during the La Niña? Past experience (Trenberth et al. 2002) suggests that global surface temperature rises at the end of and lagging El Niño, as heat comes out of the Pacific Ocean mainly in the form of moisture that is evaporated and which subsequently rains out, releasing the latent energy. Meanwhile, maximum warming of the Indian and Atlantic Oceans occurs about 5 months after the El Niño owing to sunny skies and lighter winds (less evaporative cooling), while the convective action is in the Pacific. This led to a vigorous hurricane season in the Atlantic in 2010 and extensive flooding in China and India in July, and Pakistan in August 2010 in association with the much above normal sea surface temperatures (SSTs), while the La Niña refocused action to occur in these regions and away from the Pacific domain. Very high SSTs in the Gulf of Mexico and tropical North Atlantic favored an active North Atlantic hurricane season and record rains in Colombia. Subsequently, the high SSTs around and north of Australia promoted the flooding in Queensland in December 2010 and January 2011, even as very cold conditions occurred in Europe and North America. Yet a holistic analysis of how such variations relate to the anomalous flow of energy through the climate system is generally lacking. Future work will benefit from recently released updates in the CERES dataset to span a full decade (e.g., EBAF ed2.5), but many key datasets continue to lack the duration and stability required when addressing these questions.

\subsection{Anthropogenic Climate Change}

The human influence on climate, arising mostly from the changing composition of the atmosphere (IPCC 2007), also affects energy flows. Increasing concentrations of carbon dioxide and other greenhouse gases have led to a post-2000 imbalance at the TOA of $0.9 \pm 0.5 \mathrm{~W} \mathrm{~m}^{-2}$ (Trenberth et al. 2009) (Fig. 1) that produces "global warming" or, more correctly, an energy imbalance. Tracking how much extra energy has gone back to space (Murphy et al. 2009) and where this energy has accumulated is possible, with reasonable closure for 1993-2003 (IPCC 2007); see Fig. 2. Over the past 50 years, the oceans have absorbed about $90 \%$ of the total heat added to the climate system, while the rest goes to melting sea and land ice, and warming the land surface and atmosphere. Because carbon dioxide concentrations have further increased since 2003, the amount of heat subsequently being accumulated should be even greater.

While the planetary imbalance at TOA is too small to measure directly from satellite, instruments are far more stable than they are absolutely accurate with calibration stability $<0.3 \mathrm{Wm}^{-2}$ per decade (95\% confidence) (Loeb et al. 2009). Tracking relative changes in Earth's energy by measuring solar radiation in and infrared radiation out to space, and thus changes in the net radiation, seems to be at hand (Wong et al. 2009). This includes tracking the slight decrease in solar insolation from 2000 until 2009 with the ebbing 11-year sunspot cycle, enough to offset 10-15\% of the estimated net human induced warming (Trenberth 2009). 


\section{Energy Content in the Climate System} Energy Content Change $\left(10^{22} \mathrm{~J}\right)$

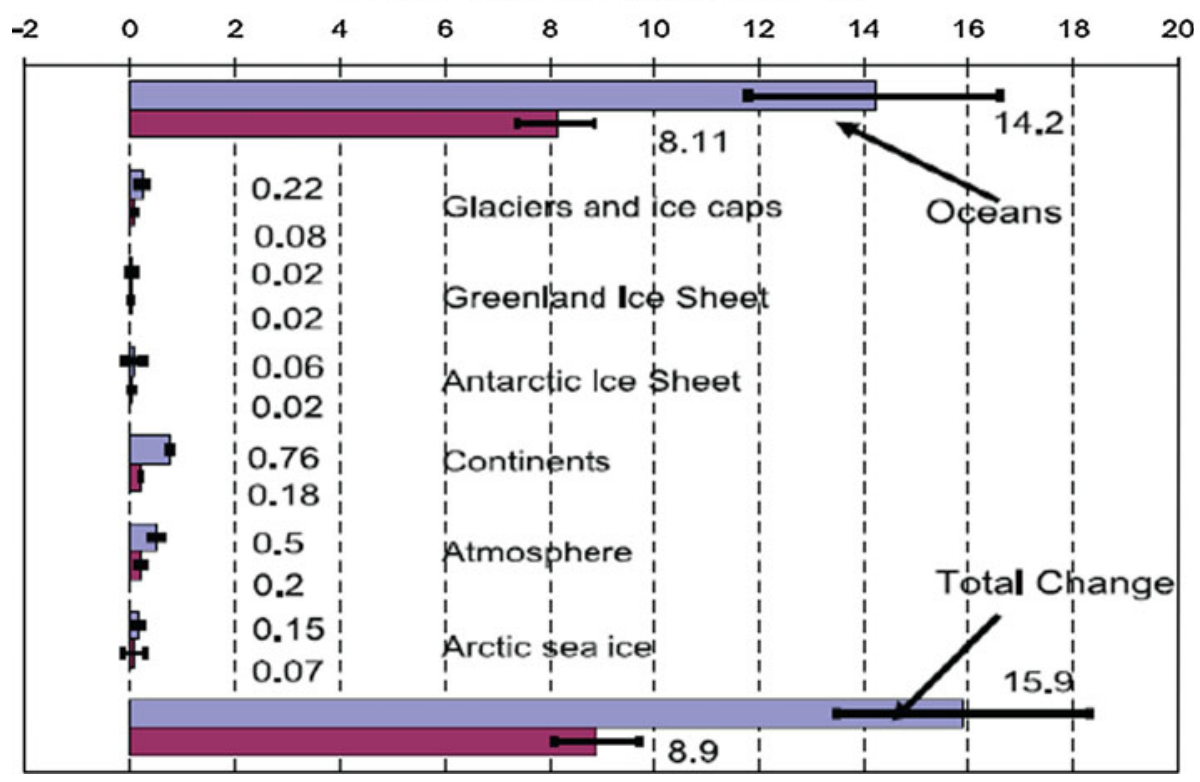

Fig. 2 Energy content changes in different components of the earth system for 2 periods (1961-2003 and 1993-2003). Blue bars are for 1961-2003; burgundy bars are for 1993-2003. Positive energy content change means an increase in stored energy (i.e., heat content in oceans, latent heat from reduced ice or sea ice volumes, heat content in the continents excluding latent heat from permafrost changes, and latent and sensible heat and potential and kinetic energy in the atmosphere). All error estimates are $90 \%$ CI. No estimate of confidence is available for the continental heat gain. Some of the results have been scaled from published results for the two respective periods. From (IPCC 2007, Figs. TS.15 and 5.4)

In 2008 for the tropical Pacific during La Niña conditions, extra TOA energy absorption was observed as expected (Wong et al. 2009); see Fig. 3. The Niño 3.4 SST index is also plotted on this figure, and the slightly delayed response of the OLR to cooler conditions in the record and especially in 2008 is clear. However, the decrease in OLR with cooler conditions is accompanied by an increase in ASR as clouds decrease in amount, leaving a pronounced net heating ( $>1.5 \mathrm{~W} \mathrm{~m}^{-2}$, cf. Loeb et al. 2009) of the planet in the cooler conditions. And so this raises the question as to whether a coherent perspective that accounts for both TOA and ocean variability can be constructed from the available observations. By 2004, the ocean observing system had reached new capabilities, as some 3,000 Argo floats populated the ocean for the first time to provide regular temperature soundings of the upper $2,000 \mathrm{~m}$, giving new confidence in the ocean heat content assessment. But ocean temperature measurements from 2004 to 2008 suggested a substantial slowing of the increase in global ocean heat content (Levitus et al. 2009; Lyman et al. 2010), precisely during the time when CERES estimates depict an increase in the planetary imbalance.

A complete assessment of all the energy in the climate system from multiple datasets (Trenberth and Fasullo 2010) is given in Fig. 4. In this figure, adapted from Trenberth and Fasullo (2010), an older preliminary version of CERES data was used and there are small differences and a slightly reduced overall trend compared with Fig. 3. The dashed black 


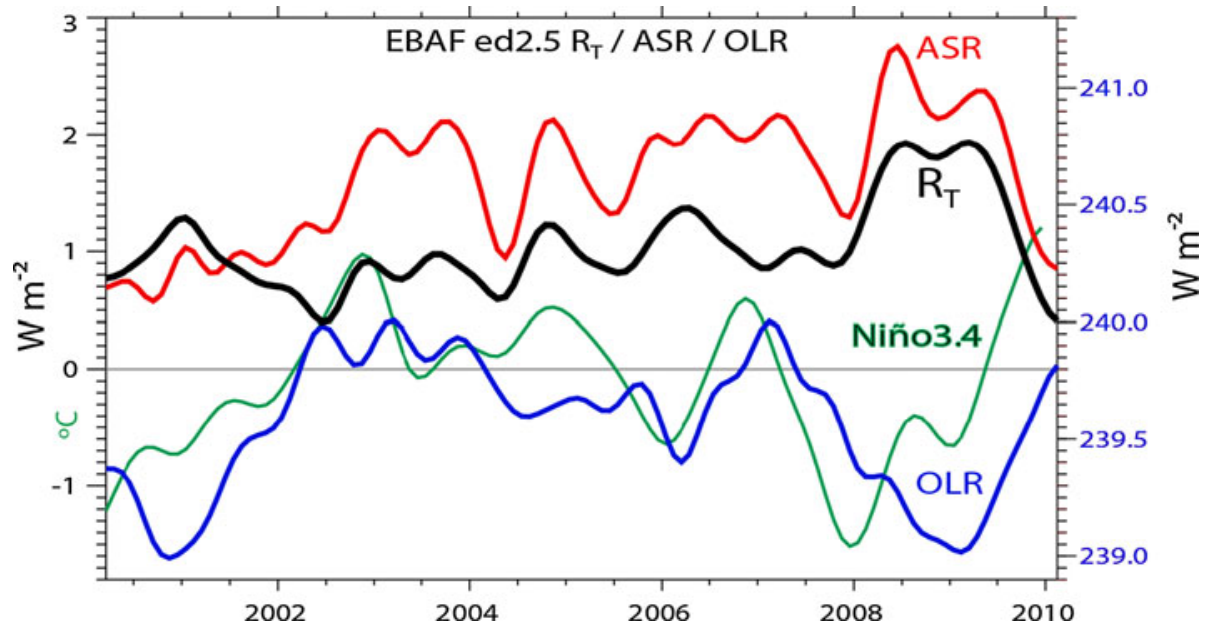

Fig. 3 Recently updated net radiation from the TOA from CERES as EBAF Ed2.5 http://www.ceres. larc.nasa.gov/products.php?product=EBAF. The ASR ( red) and OLR (blue) are given on the right axis, and the net $\left(R_{\mathrm{T}}=\mathrm{ASR}-\mathrm{OLR}\right)$ is given on the left axis (note the change in scale) in $\mathrm{W} \mathrm{m} \mathrm{m}^{-2}$. Also shown is the Niño 3.4 SST index (green) (left axis, ${ }^{\circ} \mathrm{C}$ ). The decadal low pass filter is a 13-term filter used in IPCC (2007), making it similar to a 12-month running mean

curve shows the revised CERES TOA radiation time series, updated to 2009 (from Fig. 3). Also the TOA radiation is not smoothed as much as in the published figure, thereby showing the interannual variability.

Since 1992, sea level observations from satellite altimeters at millimeter accuracy reveal a global increase of $\sim 3.2 \mathrm{~mm} \mathrm{year}^{-1}$ as a fairly linear trend (Fig. 4), although with two main blips corresponding to an enhanced rate of rise during the 1997-1998 El Niño and a brief slowdown in the 2007-2008 La Niña. Since 2003, the detailed gravity measurements from Gravity Recovery and Climate Experiment (GRACE) of the change in glacial land ice and water show an increase in mass of the ocean. This so-called eustatic component of sea level rise may have compensated for the decrease in the thermosteric (heat related expansion) component (Cazenave et al. 2009; Leuliette and Miller 2009). However, for a given amount of heat, $1 \mathrm{~mm}$ of sea level rise can be achieved much more efficiently-by a factor of 40-70 typically_by melting land ice rather than expanding the ocean (Trenberth 2009). So although some heat has gone into the record breaking loss of Arctic sea ice, and some has undoubtedly contributed to unprecedented melting of Greenland (van den Broeke et al. 2009) and Antarctica (Chen et al. 2009), these anomalies are unable to account for much of the measured TOA energy imbalance (Fig. 4). This gives rise to the concept of "missing energy".

To emphasize the discrepancy, Fig. 5 presents an alternative version of Fig. 2 for 1992-2003, as a contrast to 2004-2008. The accounting for all terms and the net imbalance is compatible with physical expectations and climate model results. Here, the net imbalance is about $0.7 \mathrm{~W} \mathrm{~m}^{-2}$ at TOA for 1992-2003 (note this is simply the sum of the terms, and was not measured at TOA). However, for the 2004-2008 period, when we do have TOA radiation measurements, the decrease in solar radiation associated with the sunspot cycle and the quiet sun in 2008 contributes somewhat, but the Ocean Heat Content (OHC) change is a lot less than in the previous period (Lyman et al. 2010) and a residual imbalance term, the missing energy, is required. 


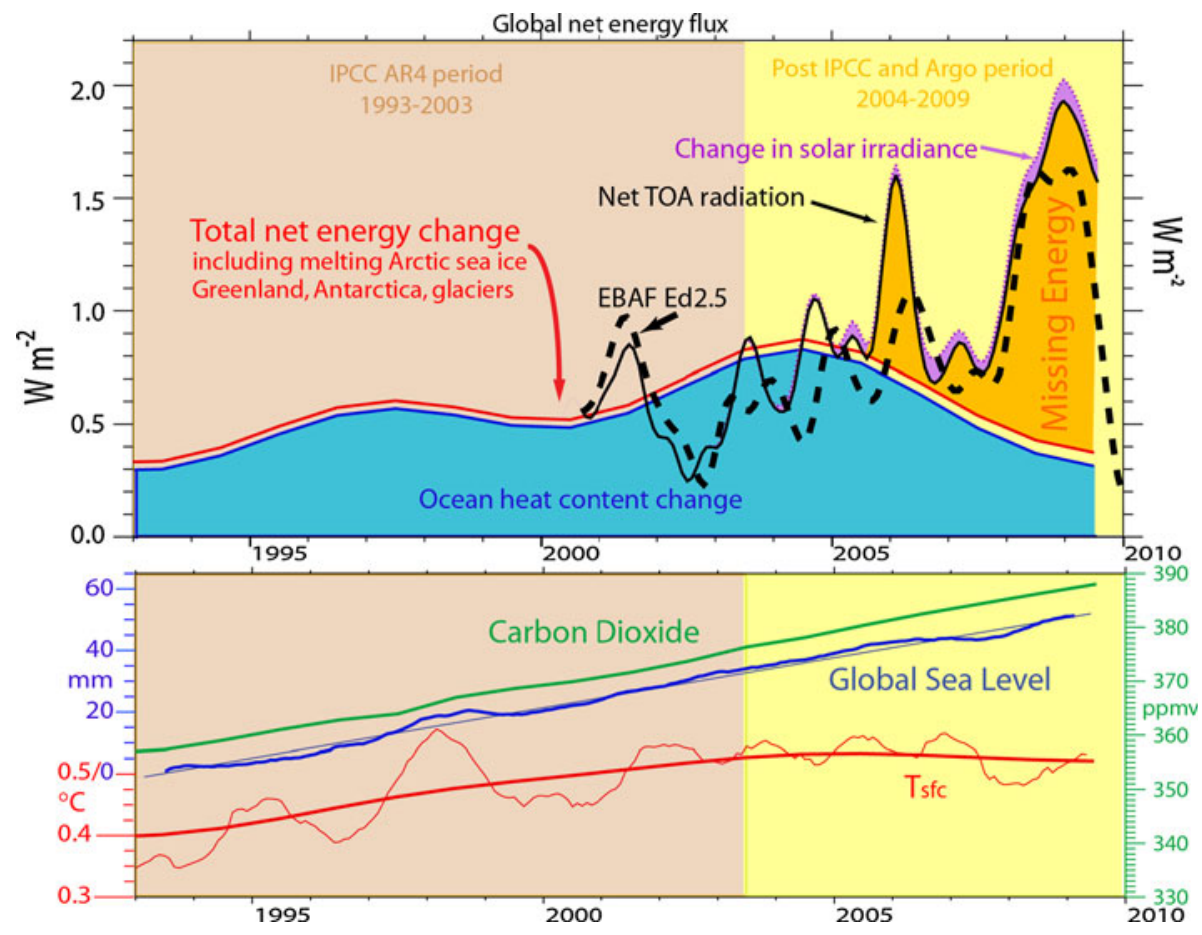

Fig. 4 The disposition of energy entering the climate system is estimated. The observed changes (lower panel; Trenberth and Fasullo 2010) show the 12-month running means of global mean surface temperature anomalies relative to 1901-2000 from NOAA [red (thin) and decadal (thick)] in ${ }^{\circ} \mathrm{C}$ (scale lower left), $\mathrm{CO}_{2}$ concentrations (green) in ppmv from NOAA (scale right), and global sea level adjusted for isostatic rebound from AVISO (blue, along with linear trend of $3.2 \mathrm{~mm} /$ year) relative to 1993, scale at left in mm). Rates of change of global energy in $\mathrm{W} \mathrm{m}^{-2}$ (top panel) are contrasted between the AR4-IPCC era 1993-2003 and the post-2003 Argo era. From 1992 to 2003, the decadal OHC changes (blue) along with the contributions from melting glaciers, ice caps, Greenland, Antarctica, and Arctic sea ice plus small contributions from land to atmosphere warming (red) suggest a total warming for the planet of $0.6 \pm 0.2 \mathrm{~W} \mathrm{~m}^{-2}$ (95\% error bars). After 2000, preliminary observations from TOA (black) referenced to the 2000 values, as used in Trenberth and Fasullo (2010), show an increasing discrepancy ( old $)$ relative to the total warming observed (red). The quiet sun changes in total solar irradiance reduce the net heating slightly (purple), but a large energy component is missing (gold). The recently revised TOA radiation from CERES, known as EBAF Ed2.5, is shown by the black dashed curve. The decadal filter is from Trenberth et al. (2007b). Adapted from Trenberth and Fasullo (2010). The monthly global surface temperature data are from NCDC, NOAA: http://www.ncdc.noaa.gov/oa/climate/research/anomalies/index.html; the global mean sea level data are from AVISO satellite altimetry data: http://www.aviso.oceanobs.com/en/news/ocean-indicators/mean-sea-level/; and the $\mathrm{CO}_{2}$ at Mauna Loa data are from NOAA http://www.esrl.noaa.gov/gmd/ccgg/trends/

One can question why, in Fig. 4, the CERES curve was attached to the total energy change curve at the beginning of the record and, indeed, this was arbitrary but based on the sense that the energy balance was reasonably explained at that time. Clearly, the variability in the CERES curve is at odds with that of the oceans, and in the original publication it was appropriately smoothed. But, by including the shorter-term variability, we can now see how much the changes in the CERES processing have altered things. It is difficult to assign error bars to all of the terms because structural errors are the main ones of importance; these arise from systematic sampling and instrumental errors for example. One interpretation of Fig. 4 


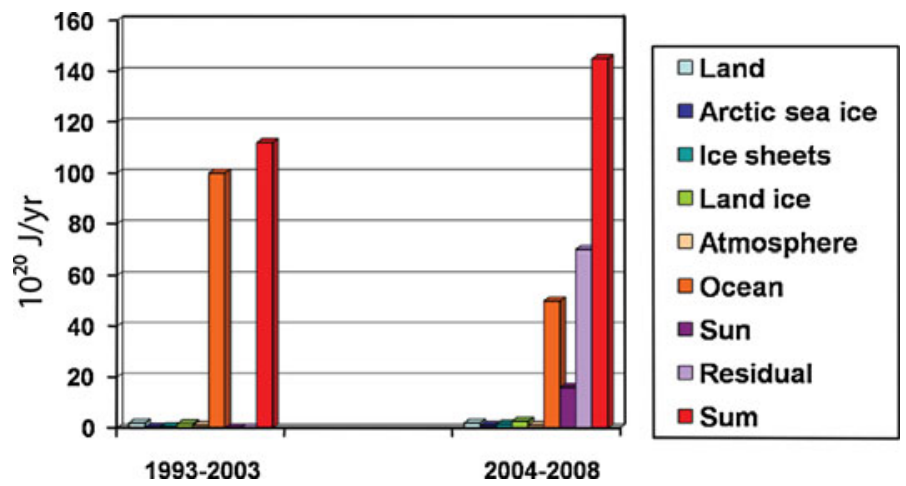

Fig. 5 The energy entering the climate system is estimated for the various components: warming of the atmosphere and land, $\mathrm{OHC}$ increase, melting of glaciers and ice caps (land ice), melting of the major ice sheets (Greenland and Antarctica), and changes in the sun. For 1993-2003, these are summed to give the total which is equivalent to about $0.7 \mathrm{~W} \mathrm{~m}^{-2}$. For 2004-2008, TOA measurements are used to provide an increment to the total based on comparisons with 2000-2003, and the quiet sun has contributed, but the sum is achieved only if a spurious residual is included. Units are $10^{20} \mathrm{~J} /$ year

is that there is no real missing energy because the error bars are not adequately accounted for and they are quite big, especially for $\mathrm{OHC}$ changes from 1 year to the next (e. g., Lyman et al. 2010), but that is really the point here. If the error bars are so big that there is no mismatch, then the values are next to useless because we cannot say anything useful about interannual or longer-term variations in energy in the climate system. As discussed below, it seems likely that undersampling of the ocean, especially the deep ocean, may well account for the main discrepancy as it is manifested at only certain times (when La Niña is present).

\subsection{Modeling Temperature Stasis for a Decade}

Further inroads into this problem will no doubt become possible as datasets are brought up to date and refined. In the meantime, we have explored the extent to which this kind of behavior occurs in the latest version of the NCAR CCSM version 4. We have examined 5 runs for the twenty-first century under the Representative Concentration Pathways RCP 4.5 , which is a forcing of the climate system under increasing greenhouse gases and changing aerosols into the twenty-first century under a stabilization of values that results in a radiative forcing of $4.5 \mathrm{~W} \mathrm{~m}^{-2}$ by the late twenty-first century, with constant forcing beyond. The details of this scenario do not matter for our current purposes. Figure 6 shows global mean surface temperature for each of the ensemble members. For one run (001), 2-decade-long periods are highlighted where there is a stasis in the surface warming. We have examined what happens with regard to energy flows during such intervals for all ensemble members and a consistent picture emerges.

At the TOA, the radiative imbalance is known exactly under these circumstances (Fig. 7). One example (Fig. 7, top left panel) shows that the net radiation at the TOA $\left(R_{\mathrm{T}}\right)$ is order $1 \mathrm{~W} \mathrm{~m}^{-2}$ into the climate system. Clearly the planet imbalance is considerable, despite the stasis at the surface, and so where is the energy going?

Examination of the changes in $\mathrm{OHC}$ shows clearly that this is the main sink. Indeed, the full-depth $\mathrm{OHC}$ continues relentlessly upwards (Fig. 7), with no hesitation at all. However, the upper $\mathrm{OHC}$ for the top $275 \mathrm{~m}$ shows the same stasis as for the surface temperature 


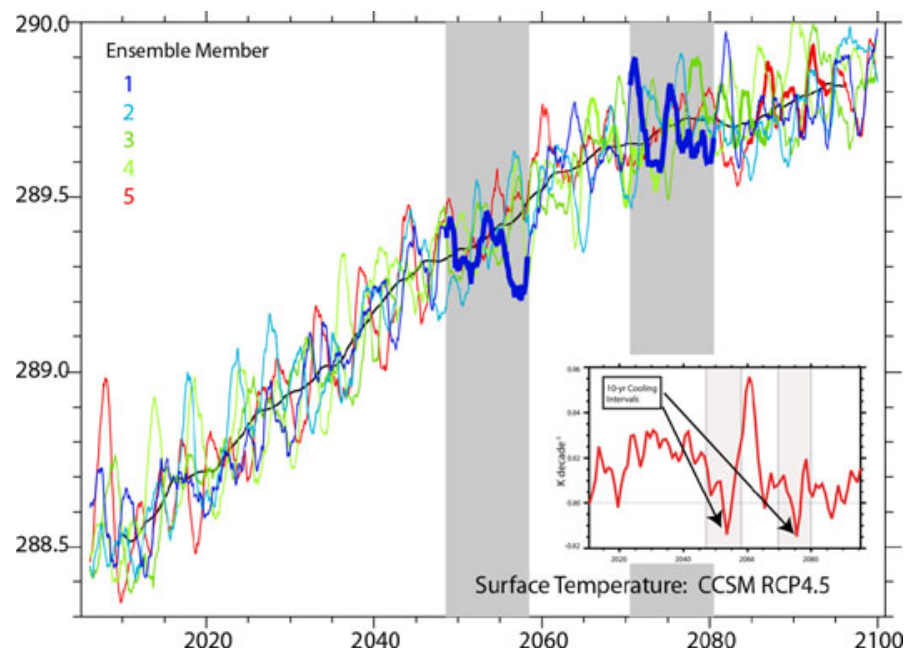

Fig. 6 Global mean surface temperatures (shown in degrees Kelvin) from CCSM4 for 5 runs into the twenty-first century, under the RCP4.5. The overall increasing temperatures are clear, and the average of the 5 runs is given by the black line. However, individual members of the ensemble show decades or longer with no increase: the inset at lower right shows the decadal rates of change for the blue run

(Fig. 7), in fact for this example the OHC (0-275 m) actually decreases. In this example (top right panel Fig. 7), roughly half of the heat is between 275 and $700 \mathrm{~m}$ depth, and the rest is below $700 \mathrm{~m}$ depth. Hence, the OHC integrated down to $700 \mathrm{~m}$ shows some slowdown, but the implication is that the missing heat is being deposited mainly in the region below $700 \mathrm{~m}$ depth. The time series also show that a swift recovery can occur at the end of the stasis period.

Further preliminary exploration of where the heat is going suggests that it is mainly in the Pacific between $40^{\circ} \mathrm{S}$ and $30^{\circ} \mathrm{N}$ and is associated with the negative phase of the Pacific Decadal Oscillation and/or La Niña events. However, this aspect is very preliminary and will be examined in much more detail elsewhere.

\section{Conclusions}

Closure of the observed energy budget over the past 5 years is elusive (Trenberth 2009; Trenberth and Fasullo 2010) although preliminary analysis of model results suggests that the ocean has absorbed considerably more heat than reported by observations, particularly below $700 \mathrm{~m}$. Song and Colberg (2011) made similar conclusions using different reasoning based on satisfying the sea level change budget. Thus, state-of-the-art observations and basic analysis are unable to fully account for recent energy variability, since they either provide an incoherent narrative or imply error bars too large to make the products useful. Only by using conservation and physical principles can we infer the likely resolution. Was the May 2009 to May 2010 El Niño a manifestation of some of the missing energy reappearing? Certainly, the overall warmth of 2010 and its manifestations around the world, as the natural variability reinforced the global warming signal, would suggest this as a reasonable hypothesis. Or is the stasis continuing or restarting with a new La Niña taking over in the 2010-2011 northern winter? It may take a few years to gain perspective on this. 


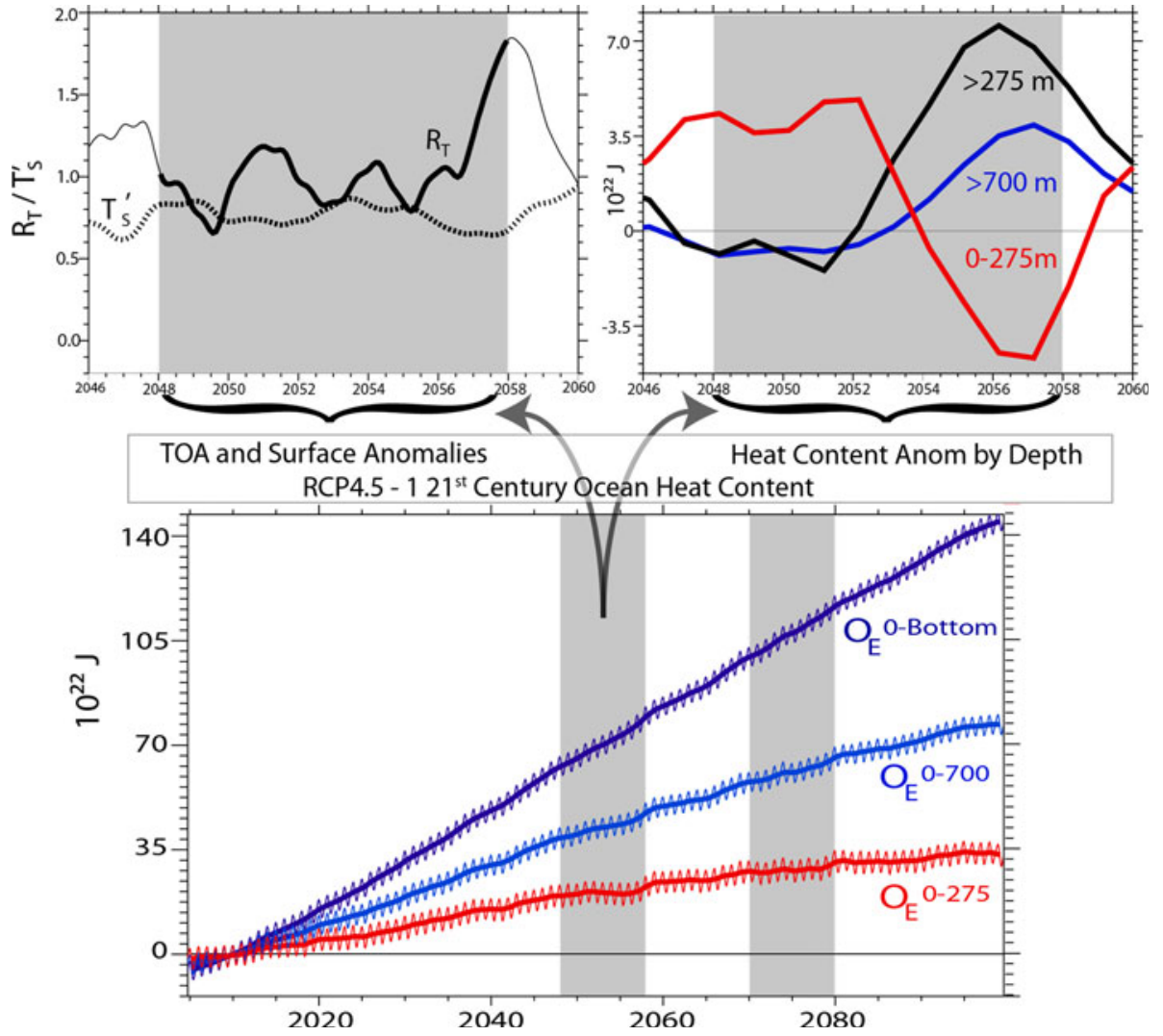

Fig. 7 The lower panel shows the perturbation relative to mean from 2005 to 2015 in $\mathrm{OHC}\left(O_{\mathrm{E}}\right)$ for layers 0-275, 0-700 m depth, and for the entire column to the bottom of the ocean in $10^{22} \mathrm{~J}$. The thin curve shows the full values and a 12-month running mean is also given. The gray vertical bars show times of stasis in the global mean surface temperature. The top left panel shows the TOA energy balance for the first stasis period 2048-2058 for the net radiation $\left(R_{\mathrm{T}}\right)$, along with the global mean surface temperature perturbation. The top right panel shows the OHC perturbation for $0-275,>275$, and $>700 \mathrm{~m}$ depth in $10^{22} \mathrm{~J}$ where the 20 years running mean has been removed

Proposals for addressing global warming now include geo-engineering whereby tiny particles are injected into the stratosphere to emulate the cooling effects of stratospheric aerosol of a volcanic eruption (Levitt and Dubner 2009). Implicitly, such proposals assume understanding and control of this process which requires detailed tracking of energy within the climate system. How can we understand whether the strong cold outbreaks of December 2009 and 2010 are simply a natural weather phenomenon, as they seem to be, or are part of some mysterious change in clouds or pollution, if we do not have adequate measurements? Tracking Earth's global energy and how it is partitioned is essential for understanding what is happening in the climate system and thus for attributing causes and predicting what comes next. It is vital information for planning adaptation to and coping with climate change.

Acknowledgments This research is partially sponsored by NASA under grant NNX09AH89G. 
Open Access This article is distributed under the terms of the Creative Commons Attribution Noncommercial License which permits any noncommercial use, distribution, and reproduction in any medium, provided the original author(s) and source are credited.

\section{References}

Cazenave A et al (2009) Sea level budget over 2003-2008: a reevaluation from GRACE space gravimetry satellite altimetry and Argo. Glob Planet Chang 65:83-88. doi:10:1-16/j.gloplacha.2008.10.004

Chen JL, Wilson CR, Blankenship D, Tapley BD (2009) Accelerated Antarctic ice loss from satellite gravity measurements. Nat Geosci 2:859-862

Costa SMS, Shine KP (2011) Outgoing longwave radiation due to directly-transmitted surface emission. J Atmos Sci (submitted).

Fasullo JT, Trenberth KE (2008a) The annual cycle of the energy budget: Pt I. Global mean and land-ocean exchanges. J Clim 21:2297-2313

Fasullo JT, Trenberth KE (2008b) The annual cycle of the energy budget: Pt II. Meridional structures and poleward transports. J Clim 21:2314-2326

Haynes JM, Stephens GL (2007) Tropical oceanic cloudiness and the incidence of precipitation: early results from CloudSat. Geophys Res Lett 34:L09811. doi:10.1029/2007GL029335

Huffman GJ, Adler RF, Bolvin DT, Gu G (2009) Improving the global precipitation record: GPCP version 2.1. Geophys Res Lett 36:L17808. doi:10.1029/2009GL040000

IPCC (2007) In: Solomon S et al (eds) Climate change 2007: the physical science basis. Cambridge University Press, New York, p 996

Kato S, et al. (2011) Improvements of top-of-atmosphere and surface irradiance computations with CALIPSO-, CloudSat-, and MODIS-derived cloud and aerosol properties. J Geophys Res 116. doi:10.1029/ 2011JD016050

Kiehl JT, Trenberth KE (1997) Earth's annual global mean energy budget. Bull Am Meteor Soc 78:197-208

Kim D, Ramanathan V (2008) Solar radiation and radiative forcing due to aerosols. J Geophys Res 113:D02203. doi:10.1029/2007JD008434

Leuliette EW, Miller L (2009) Closing the sea level rise budget with altimetry, Argo, and GRACE. Geophys Res Lett 36:L04608. doi:10.1029/2008GL036010

Levitt S, Dubner S (2009) Superfreakonomics: global cooling, patriotic prostitutes, and why suicide bombers should buy life insurance. Harper Collins, New York, p 288. ISBN: 100060889579

Levitus S et al (2009) Global ocean heat content 1955-2008 in light of recently revealed instrumentation problems. Geophys Res Lett 36:L07608. doi:10.1029/2008GL037155

Loeb NG et al (2009) Towards optimal closure of the earth's top-of-atmosphere radiation budget. J Clim 22:748-766

Lyman JM, Good SA, Gouretski VV, Ishii M, Johnson GC, Palmer MD, Smith DM, Willis JK (2010) Robust warming of the global upper ocean. Nature 465:334-337

Murphy DM et al (2009) An observationally based energy balance for the earth since 1950. J Geophys Res 114:D17107. doi:10.1029/2009JD012105

Perlwitz J, Hoerling M, Eischeid J, Xu T, Kumar A (2009) A strong bout of natural cooling in 2008. Geophys Res Lett 36:L23706. doi:10.1029/2009GL041188

Schlosser CA, Houser PR (2007) Assessing a satellite-era perspective of the global water cycle. J Clim 20:1316-1338

Song YT, Colberg F (2011) Deep ocean warming assessed from altimeters, gravity recovery and climate experiment, in situ measurements, and a non-Boussinesq ocean general circulation model. J Geophys Res 116:C02020. doi:10.1029/2010JC006601

Stephens GL, Haynes JM (2007) Near global observations of the warm rain coalescence process. Geophys Res Lett 34:L20805. doi:10.1029/2007GL030259

Stephens GL et al (2002) The CloudSat mission and the A-Train. Bull Am Meteor Soc 83:1771-1790

Trenberth KE (2009) An imperative for adapting to climate change: tracking earth's global energy. Curr Opin Env Sustain 1:19-27

Trenberth KE, Fasullo JT (2008) An observational estimate of ocean energy divergence. J Phys Oceanogr 38:984-999

Trenberth KE, Fasullo JT (2010) Tracking earth's energy. Science 328:316-317

Trenberth KE et al (1998) Progress during TOGA in understanding and modeling global tele connections associated with tropical sea surface temperatures. J Geophys Res 103:14291-14324 
Trenberth KE, Caron JM, Stepaniak DP, Worley S (2002) Evolution of El Niño southern oscillation and global atmospheric surface temperatures. J Geophys Res 107(D8):4065. doi:10.1029/2000JD000298

Trenberth KE, Smith L, Qian T, Dai A, Fasullo J (2007a) Estimates of the global water budget and its annual cycle using observational and model data. J Hydrometeorol 8:758-769

Trenberth KE et al (2007b) Observations: surface and atmospheric climate change. In: Solomon S, Qin D, Manning M, Chen Z, Marquis MC, Averyt KB, Tignor M, Miller HL (eds) Climate change 2007. The physical science basis. Contribution of WG 1 to the fourth assessment report of the intergovernmental panel on climate change. Cambridge University Press, Cambridge, pp 235-336

Trenberth KE, Fasullo JT, Kiehl J (2009) Earth's global energy budget. Bull Am Meteor Soc 90:311-323

van den Broeke M et al (2009) Partitioning recent Greenland mass loss. Science 326:984-986

Wild M, Ohmura A, Gilgen H, Morcrette JJ, Slingo A (2001) Evaluation of downward longwave radiation in general circulation models. J Clim 14:3227-3239

Wong T, Stackhouse PW Jr, Kratz DP, Wilber AC (2009) Earth radiation budget at top-of-atmosphere [in "state of the climate in 2008"]. Bull Am Meteor Soc 90:S33-S34

Yu LS, Weller RA (2007) Objectively analyzed air-sea heat fluxes for the global ice-free oceans (1981-2005). Bull Am Meteor Soc 88:527-539

Zhang Y, Rossow WB, Stackhouse PW Jr (2006) Comparison of different global information sources used in surface radiative flux calculation: radiative properties of the near-surface atmosphere. J Geophys Res 111:D13106. doi:10.1029/2005JD006873 